CORROSION OF Fe-10A1-Cr ALLOYS BY COAL CHAR

RECEIVED

LAWRENCE

BERKGLE ABOKATORY

B. A. Gordon and V. Nagarajan

\section{JAN 271978}

LIBRARY AND

DOCUMENTS SECTION

\author{
October 1977 \\ Prepared for the U. S. Department of Energy \\ under Contract W-7405-ENG-48
}

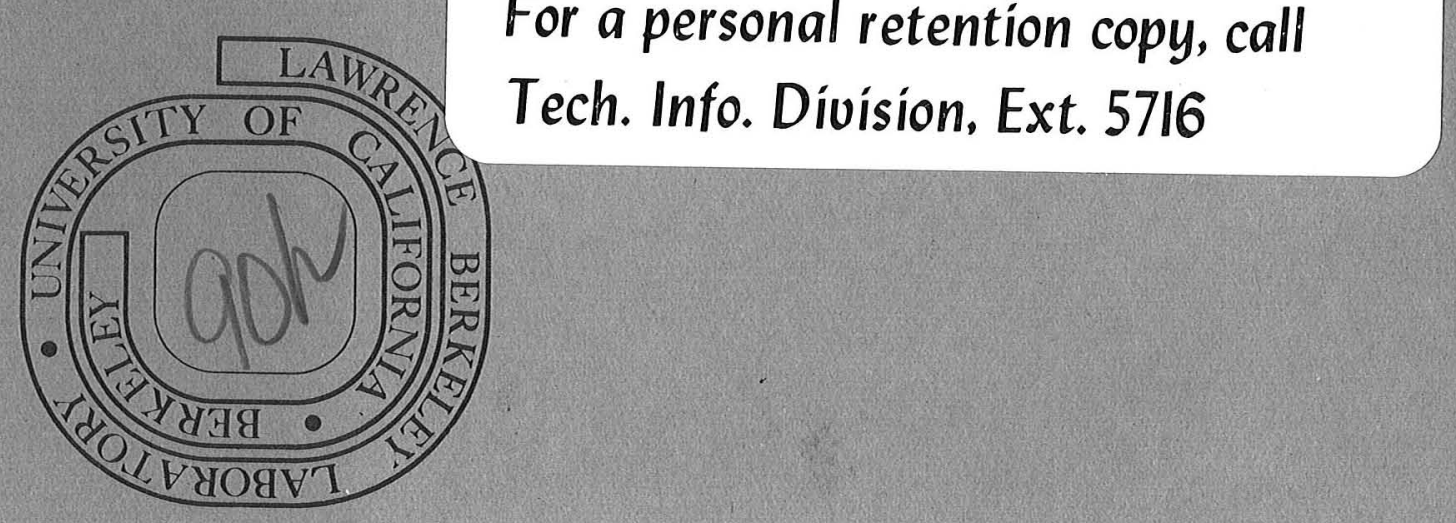

TWO-WEEK LOAN COPY

This is a Library Circulating Copy

which may be borrowed for two weeks.

For a personal retention copy, call

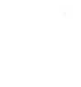




\section{LEGAL NOTICE}

This report was prepared as an account of work sponsored by the United States Government. Neither the United States nor the Department of Energy, nor any of their employees, nor any of their contractors, subcontractors, or their employees, makes any warranty, express or implied, or assumes any legal liability or responsibility for the accuracy, completeness or usefulness of any information, apparatus, product or process disclosed, or represents that its use would not infringe privately owned rights. 


\author{
Corrosion of Fe-10Al-Cr Alloys by Coal Char \\ B. A. Gordon and V. Nagarajan
}

Materials and Molecular Research Division, Lawrence Berkeley Laboratory and Department of Chemical Engineering, University of California, Berkeley, California 94720

Octobex, 1977

\begin{abstract}
Corrosion of iron-base alloys at $982^{\circ} \mathrm{C}\left(1800^{\circ} \mathrm{F}\right)$ by coal char is observed and the phase morphologies discussed. No sulfidation was observed at 50 hours exposure. After 100 hours, intemal aluminum rich sulfides were observed along with thick outex scales of ixon oxide. The species causing the high-temperature induced corrosion are probably sulfides and sulfates, present in most coal chars. Possible mechanisms for the corrosion are also discussed.
\end{abstract}

Key words: iron-aluminum-chromium, corrosion, coal char

\footnotetext{
*Presently in Department of Materials Science \& Mineral Engineering.
} 

INTRODUCTION

With the current energy crisis, increased attention has been focussed on coal as an abundant source of fossil fuel. A promising way to utilize coal is to convert it to synthetic natural gas (SNG) and petroleum-type products. There are problems in coal-gasification because at the reaction temperatures of $870^{\circ}$ to $982^{\circ} \mathrm{C}\left(1600^{\circ}\right.$ to $\left.1800^{\circ} \mathrm{F}\right)$ and pressures of up to 60 to 70 atmosphexes, the reaction products become quite corrosive to containment materials.

The off-gas from a typical gasifier contains large percentages of $\mathrm{CO}_{2} \mathrm{CO}_{2}, \mathrm{H}_{2}, \mathrm{CH}_{4}, \mathrm{H}_{2} \mathrm{O}$, and $\mathrm{H}_{2} \mathrm{~S}$, (1) These gases, paxticularly $\mathrm{H}_{2} \mathrm{~S}$, can be quite corrosive. To compound the problem, the particulate by-product of gasification is char, a light, friable material which contains (see Table 1) about $25-50 \%$ fixed carbon and the balance inorganic oxides, sulfides, and sulfates (including FeS and $\mathrm{CaSO}_{4}$, respectively)。(2)

Considerable work is being done on gas-metal corrosion of alloys, but very little has been done on corrosion of alloys by coal char. This work describes some preliminary screening experiments to observe the behavior of char on Fe-10Al and Fe-10Al-Cr alloys at coal-gasifier operating temperatures.

This investigation is concerned with iron-base alloys that form external $\mathrm{Al}_{2} \mathrm{O}_{3}$ scales. In alumina forming alloys the transition from internal to extexnal $\mathrm{Al}_{2} \mathrm{O}_{3}$ formation occurs axound $7 \mathrm{wt} \%$. To be certain of foxming an external $\mathrm{Al}_{2} \mathrm{O}_{3}$ scale, $10 \mathrm{wt} . \% \mathrm{Al}$ was added to the alloys. 
EXPERTMENTAL,

The fumace used was a Lindberg horizontal tube furnace equipped With a $3.8 \mathrm{~cm}$ o.d. mullite tube. The ends of the tube were sealed with compresston-type viton owing seals. For introduction of the samples into the heat zone, one end of the furance was equipped with a $3.8 \mathrm{~cm} i \mathrm{~d}$ ball valve. Tor introduction of the appropriate gas, the other end was equipped with a gas inlet nozzle, netexing valve, and a vacuum pump to remove all traces of ait from the fumace.

The temperature of the Eurnace was calibrated before and after each run since there was no provision for continuous, on-line monitoring. Temperature variation was $\pm 2^{\circ} \mathrm{C}$ as determined by a long-term calibration using a chromel-alumel themocouple and Doric digital indicator.

The samples were prepared by cutting coupons about 1 cn $x 1$ cm $x$ $0.5 \mathrm{~cm}$. All six faces were polished to $600 \mathrm{grit}$ and washed with ethanol. The gas used was argon with approximately $6-10$ ppm of oxygen as an impurity. The carbon carbon monoxide equilibrium kept the ${ }^{p} \mathrm{O}_{2}$ much lower than chat present in the argon.

The sample coupons were placed in a high-purdty alumina boat half-filled with synthane process coal chax from IIInois $\mid$ l6 coal and thserted into the funace which was kept at a constant $982^{\circ}+2^{\circ} \mathrm{C}$. All three samples were exposed in the same boat, with about $1 \mathrm{~cm}$ between samples. The exposure times wexe 24 hours, 50 hours, and 100 houxs. At the end of the runs, the samples were removed, and their surfaces exanined by scaning electron microscopy (SEM). They were then mounted in bakelite, crosswectoned, and once again examined by SEM and energy dispersive xuray analysig (EDAX). 
RESULTS

All three alloys had suffered corrosion by chax. Although there was no catastrophic corrosion up to 50 hours, the Fe-10Al and Fe-10A1-5Cr alloys were catastrophically corroded at the end of the 100 hour run. The $-10 \mathrm{Cr}$ containing alloy suffered only very litcle external and internal corrosion. No sulfux was detected in any of the alloys after 24 or 50 hours exposure.

Figure 1 shows cross sections of Fe-10A1, Fe-10A1-5Cr, and Fe-10Al-10Cr alloys after 24 hours exposure to char at $982^{\circ} \mathrm{C}$. Scanning electron micrographs of the surface of the samples show formation of an uneven aluminum oxide layer with several thick protrusions. Crosssectioning through these protrusions shows that they are primarily $\mathrm{Al}_{2} \mathrm{O}_{3}$ (Figure 1a,b). Both the Fe-10Al-5Cr and Fe-10Al-10Cr alloys showed considerable $\mathrm{Al}_{2} \mathrm{O}_{3}$ penetration into the alloy (Figures $1 \mathrm{c}, \mathrm{e}$ )。 The formation of uneven $\mathrm{Al}_{2} \mathrm{O}_{3}$ layexs on the Fe-10Al-10Cr alloy left behind chromium-enriched regions in the alloy near the scale-alloy interface (Figures If,g). There was much less enrichment in the $-5 \mathrm{Cr}$ system. All of the alloys exhibited uneven penetration as shown in Figures $1 c$ and $e$.

After 50 hours exposure, the situation was much the same. The appearance of the three alloys was similar to that show in Figure 1. The surface scale appeared rough and uneven. Penetration into the bulk of the alloy was not noticeably greater in any of the three systems as compared with 24 hours exposure.

The situation changed dramatically after 100 houxs exposure. Figure 2 shows electron micxographs of the surfaces of a11 three alloys 
aftex 100 hours. The surface has extensive scaling which appears to have spread out, slag-1ike, from the comers and edges. Under high magnification (Figures 2b, d), this expanded scale consists of long, needle-like protrusions with a smooth, molten surface appearance. EDAX analysis of these needles reveals that they are almost entirely Iron oxide. Such growths appeared on the Fe-10AI and Fe-10Al-5Cr alloys but not on the rew10Al-10Cr alloy. Instead, on the -10cr alloy, small, oval protrusions of $\mathrm{Al}_{2} \mathrm{O}_{3}$ formed after 100 hours exposure.

Cross-sectioning of the alloys revealed that although the scale Was predomanatiy iron oxide, increasing amounts of aluninum began to appear in the scale towards the uncorroded metal. Finally, at the interface of the uncorroded alloy and the furthest penetration of the corrosion, sulfur appears, invariably as aluminum-rich sulfide. These sulfides appear as grey or black needles in optical micrographs (Figure $3 a, b$ ) and occur only in the Fe-10Al and -5Cr alloys. No such penetration occurs in the -10cr alloy. Plgure 4 shows an BDAX analysis of such a region in the Fe-10Al-5Cx syster. The x-tay mapping techique provides a good contrast between the aluminum and sulfur-rich regions and the aluminum and sulfur-poox regions. Figures $4 b-d$ show that the daxk grey inclusions are rich in aluminum and sulfur and poor in Fe. Further examination reveals that there is a chromium-rich region that appears as a thin but uneven layer in the extemal scale (rigure 4e). Underneath that but still in the external scale is an aluminum-rich region followed by a region of apparently unreacted alloy. Next comes the poxtion of the alloy penetrated by aluminum sulfide. 
Aftex the 100 hours tests, the coal char had taken on a red, powdery appearance, typical of $\mathrm{Fe}_{2} \mathrm{O}_{3}$. This implied that between 50 and 100 hours of exposure, all the carbon had been oxidized and lost from the system. The $\mathrm{P}_{\mathrm{O}_{2}}$ subsequently had risen to the level present in the argon, about 6-10 ppm (about $10^{-5}$ atmospheres). This is sufficient to oxidize all the FeO and Fes in the chax to $\mathrm{Fe}_{2} \mathrm{O}_{3}$.

DISCUSSION

The partial pressure of oxygen over the char is about $10^{-5}$ to $10^{-6}$ atmosphere. At the char-alloy interface in these experiments, the partial pressure of oxygen should be much lower than $10^{-6}$ atmosphere because of the reaction between carbon in the char and oxygen in the argon. Thermodynamically, it should be below $10^{-19}$ atmosphere. After 24 and 50 hours exposure, there was still sufficient carbon left to maintain this situation, but between 50 and 100 hours the carbon was completely oxidized, and the oxygen partial pressure permitted to xise to that level present in the axgon.

After both 24 hours and 50 hours exposure, only an uneven $\mathrm{Al}_{2} \mathrm{O}_{3}$ layer was formed on any of the alloys. At the conditions presumed to exist at the charalloy incerface, $\mathrm{Al}_{2} \mathrm{O}_{3}$ is the only stable phase. The reasons for the uneven nature of this layer are not well understood, and it may be due to the differences in the availability and partial pressure of oxygen at the char-alloy interface. Between 50 and 100 hours, extensive scaling appears on both the binary and the $-5 \mathrm{Cx}$ alloy. This corrosion seems to have formed a liquid slag. Cross sectioning of the alloys shows extensive internal penetration and the 
formation of aluminum rich sulfide inclusions. This indicates that the slag formed might initially be a liquid sulfide or an oxide-gulfide eutectic which later becomes completely oxidized.

Examination of the composition of char (presented in rable 1) and the morphology of the corrosion of the alloys reveals that sulfur for the corrosion reaction must have come from Fes and/or $\mathrm{CaSO}_{4}$. It Is difficult to pimpolnt whether Fes or CaSO, contributed the major anount of sulfur for the corrosion reaction, but some inferences can be made from thermodynamic considexations. Examination of cao $\mathrm{CaSO}_{4}$ (7) and FeO- Fes (5) stability phase diagrams shows that both $\mathrm{CaSO}_{4}$ and Fes could decompose to donate sulfux for the reaction. Furthemoxe, it is also evident that increasing the partial pressure of oxygen should increase the partial pressure of sulfur by oxidation of Fes. Decreasing the partial pressure of oxygen should increase the partial pressure of sulfur by reduction of $\mathrm{CaSO}_{4}$. The experimental observation that no sulfidation occurred when carbon was stili present (and the $\mathrm{P}_{\mathrm{O}_{2}}$ low) is more consistent with the hypothesis that Fes is the principal corroding species. Further experiments are being carried out with controlled $P_{O_{2}}$ to demonstrate clearly the conditions under which $\mathrm{FeS}_{\text {and }} \mathrm{CaSO}_{4}$ become major corroding species.

At the conditions presumed to exist at the char alloy interface, alminum-rich sulfides are unstable, and the alloys should form only $\mathrm{AL}_{2} \mathrm{O}_{3}$ scales. But the partial pressure of oxyren beneath the $\mathrm{Al}_{2} \mathrm{O}_{3}$ scale will be extremely small, and so aluminumich sulfides can form if the sulfur can diffuse through the external $\mathrm{Al}_{2} \mathrm{O}_{3}$ scale. The 
experimental results indicate that sulfur does indeed diffuse through the external scale.

The experimental observation that at the end of 100 hours, two of the three alloys had slagged and the remainder of the char was porous suggests that the slag is formed as a result of the presence of the alloy and not within the char itself. In practical situations, the slagging type of corrosion may be prevented if the partial pressure of oxygen is properly regulated so the decomposition of Fes is minimized.

\section{CONCLUSIONS}

Char contains sufficient fixed inorganic sulfur to induce corrosion in iron-base alloys. At sufficiently high temperatures and oxygen partial pressures, this corrosion can appear in the form of a liquid slag on the surface of the alloy. Internal sulfides can also form as a result of this kind of attack leading to catastrophic failure of the alloy.

\section{ACKNOWLEDGEMENTS}

The authors are grateful to Professor Wayne Worrel1, Dr. John Stringex, Mx. Alan Levy, and especially Professor John Newman for their assistance in the pursuit of this work.

This research was supported by the United States Energy Research and Development Administration. 
1. William W. Bodle and Kixit C. Vyas, 0il and Gas Journal, 73(1974).

2. Stan Gasior, Pittsburgh Energy Research Center, private commuication.

3. D. B. Rao and Howard Nelson, "Sulfidation of 310 Stainless Steel at Sulfur Potentials Encountered in Coal Conversion Systems", NASA TM X-73, 166.

4. Robert Rapp, "Proceed. of Workshop on Naterials Problems and Research opportunities in Coal Conversion", Vol. II, spons, by NSF and OCR, Apriz 13-16, 1974, Columbus, Ohjo, pp. 313-334.

5. B. A. Cordon, Wayne Worre11, V. Nagarajan, to be publjshed.

6. Jo Stringer and D. P. Whitcle, Rev. Intontes. Temp. et Refract, $14,6(1977)$.

7. John Stringer, private commulcation. 


\section{$-9=$}

\begin{tabular}{|c|c|}
\hline $\mathrm{ASH}$ & Percentage \\
\hline $\mathrm{SLO}_{2}$ & 46.3 \\
$\mathrm{Al}_{2} \mathrm{O}_{3}$ & 15.2 \\
$\mathrm{Fe}_{2} \mathrm{O}_{3}$ & 14.9 \\
$\mathrm{CoO}$ & 6.5 \\
$\mathrm{MgO}_{2}$ & 1.1 \\
$\mathrm{TiO}_{2}$ & 0.6 \\
$\mathrm{P}_{2} \mathrm{O}_{5}$ & 0.2 \\
$\mathrm{Na}_{2} \mathrm{O}_{2}$ & 3.0 \\
$\mathrm{~K}_{2} \mathrm{O}$ & 1.8 \\
$\mathrm{SO}_{3}$ & 5.4 \\
& as sulfate \& sulfide \\
\hline
\end{tabular}

\begin{tabular}{|c|c|}
\hline CHAR & Percentage \\
\hline Fixed carbon & $25-50 \%$ \\
ash & $45-70 \%$ \\
sulfur & $<1.5 \%$ \\
high boiling cars & $<4 \%$ \\
\hline
\end{tabular}

Table 1. Composition of IIlinois 非 ash and coal char. 
Figure 1. Cross sections of samples exposed to char and argon $\left(+6-10\right.$ ppm $\left.o_{2}\right)$ for 24 hours at $982^{\circ} \mathrm{C}$. The attached $x-r a y$ maps show elemental distributions as indicated.

(a) Fe-10A1 alloy. Note the heavy, thick protrusion. (b) A1 X-ray map of protrusion indicates that protrusion is $\mathrm{Al}_{2} \mathrm{O}_{3}$. (c) Fe-10A1-5Cr alloy. Note the heavy, dark gray inclusion. (d) AI x-ray map indicates inclusions are $\mathrm{Al}_{2} \mathrm{O}_{3} \cdot$ (e) Fe-10AI-10Cr alloy with dark gray inclusions. (f) Cxwap showing $\mathrm{Cr}$ entichment adjacent to but not in scale. (g) Al-map showing scale is $\mathrm{Al}_{2} \mathrm{O}_{3}$. 


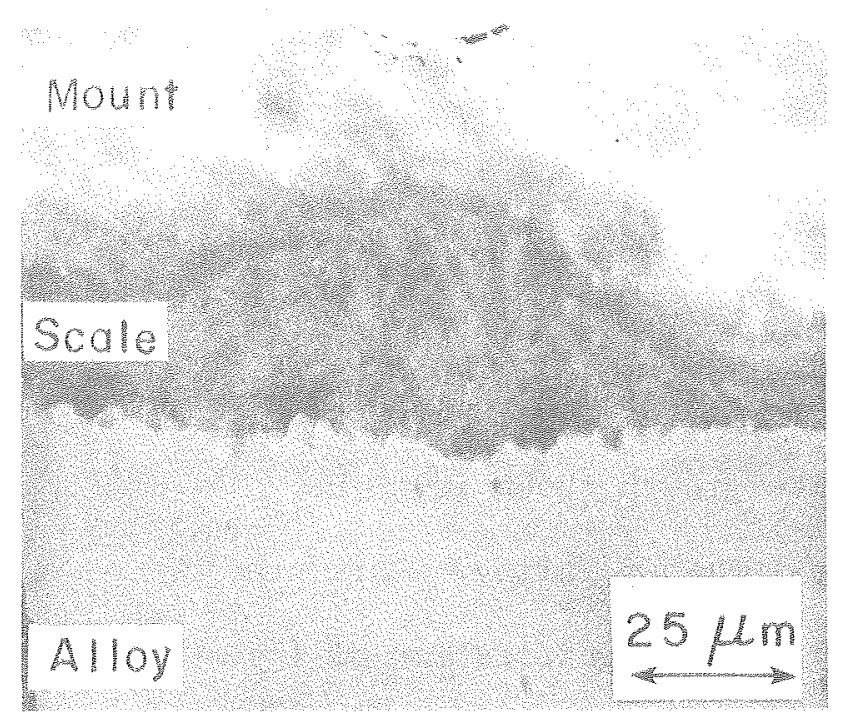

(a)

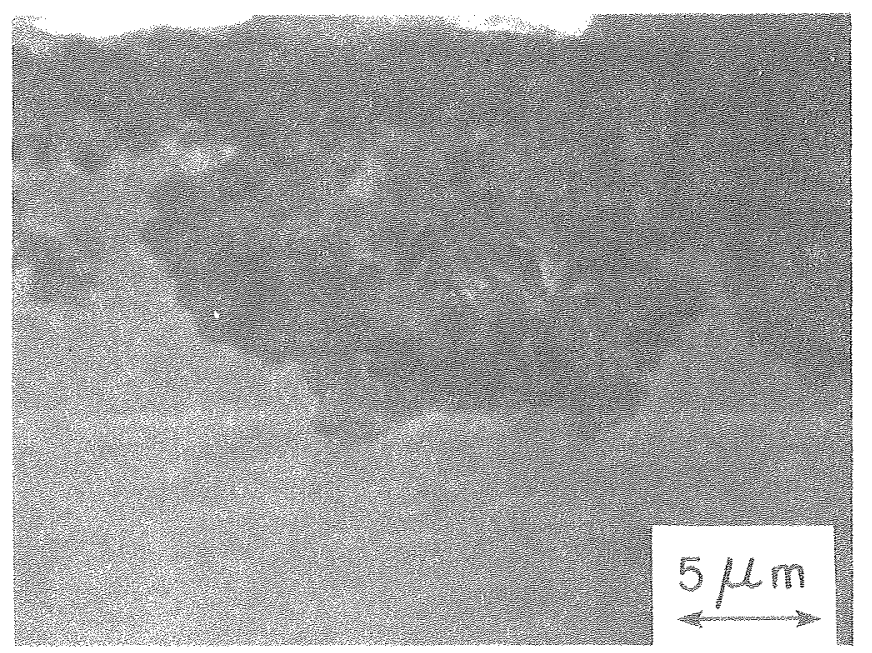

(c)

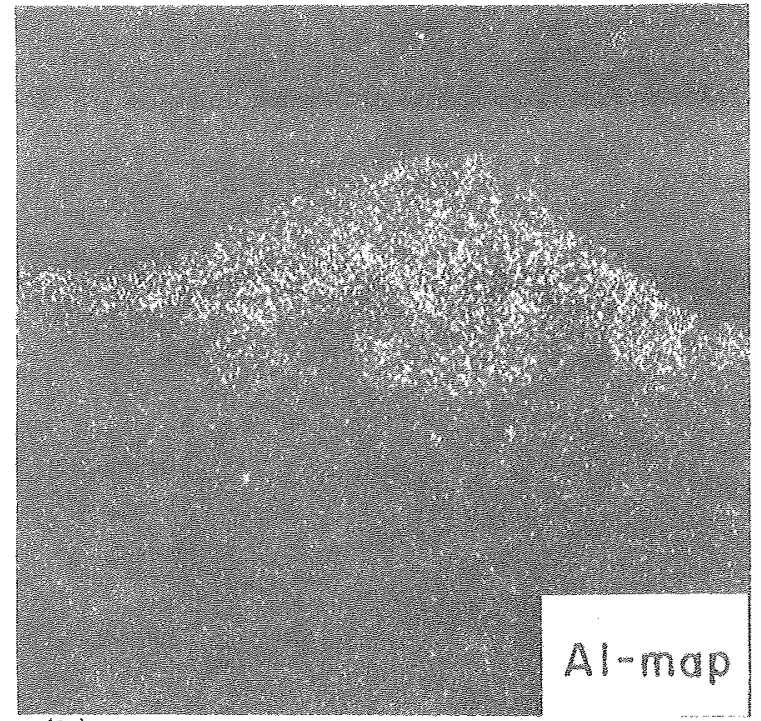

(b)

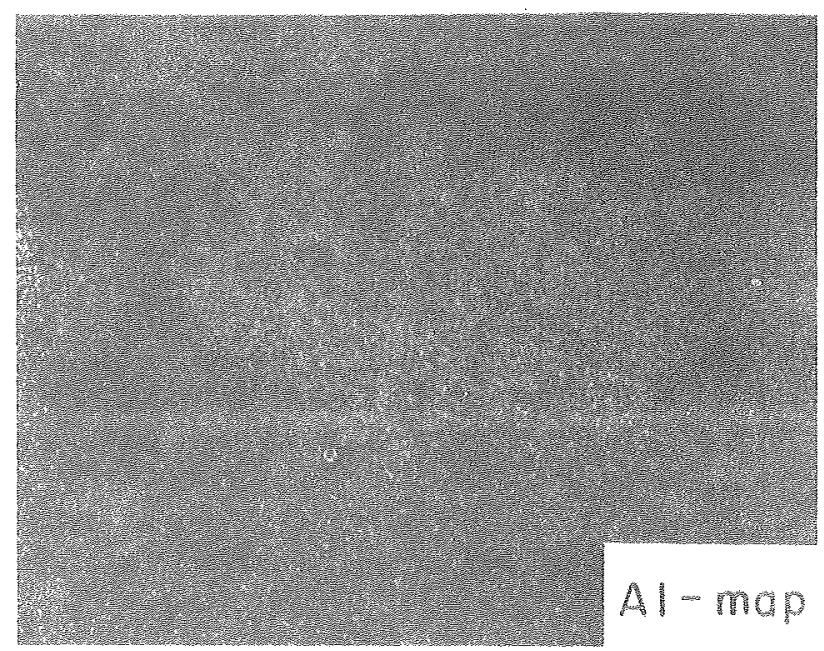

(d)

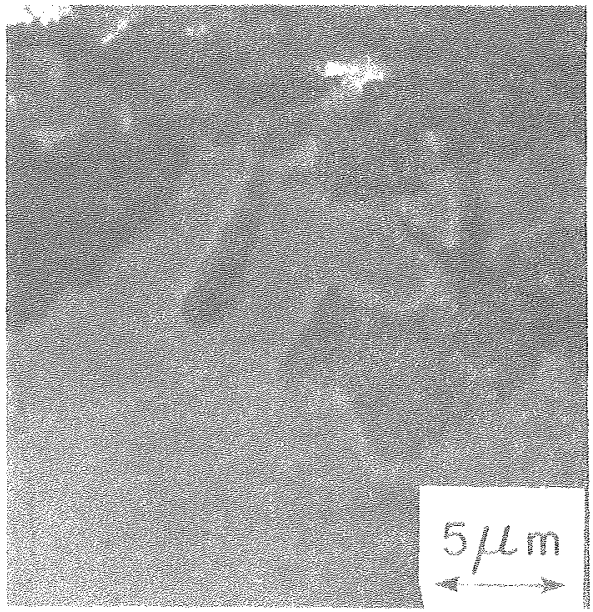

(e)

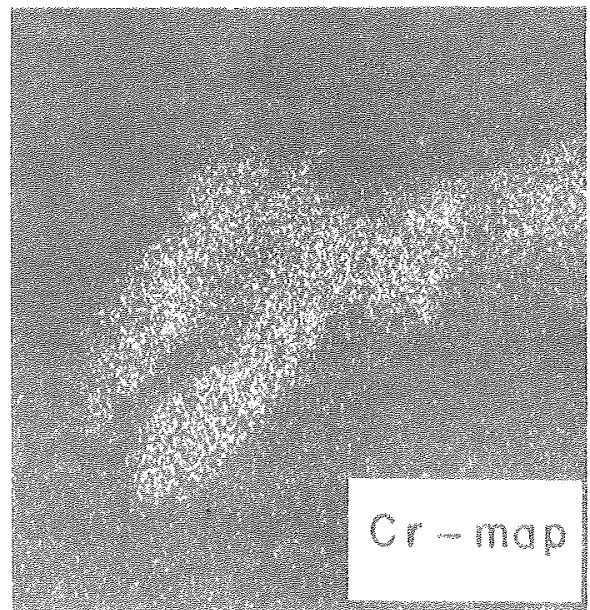

(f)

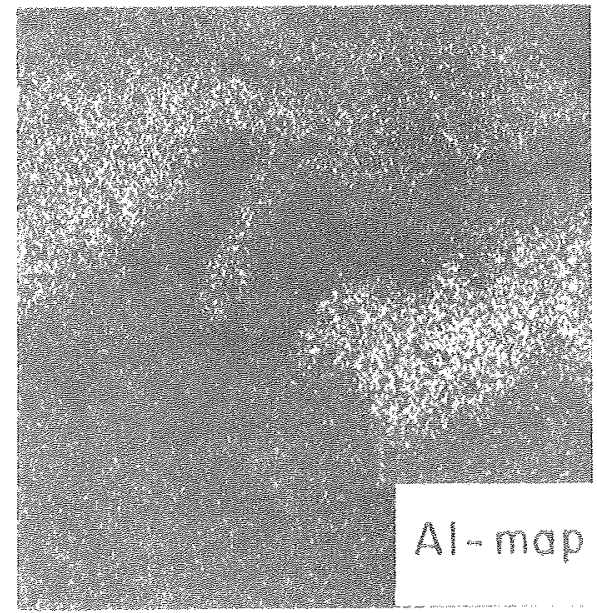

(g) 
Figure 2. Surface micrographs of samples exposed to char and argon (+6-10 $\mathrm{ppm} \mathrm{O}_{2}$ ) for 100 hours at $982^{\circ} \mathrm{C}$. (a) Fe-10A1 alloy. Dark gray region is expanded scale. (b) High-magnification of (a). Analysis of needle-like growth show it to be primarily iron oxide. (c) Fe-10A1-5Cr alloy. Dark gray region is expanded scale. (d) High magnification of (c). EDAX analysis also shows it to be iron oxide. (e) Fe-10A1-10Cr. No expanded scale but oval areas are thicker $\mathrm{Al}_{2} \mathrm{O}_{3}$ regions on surface. 

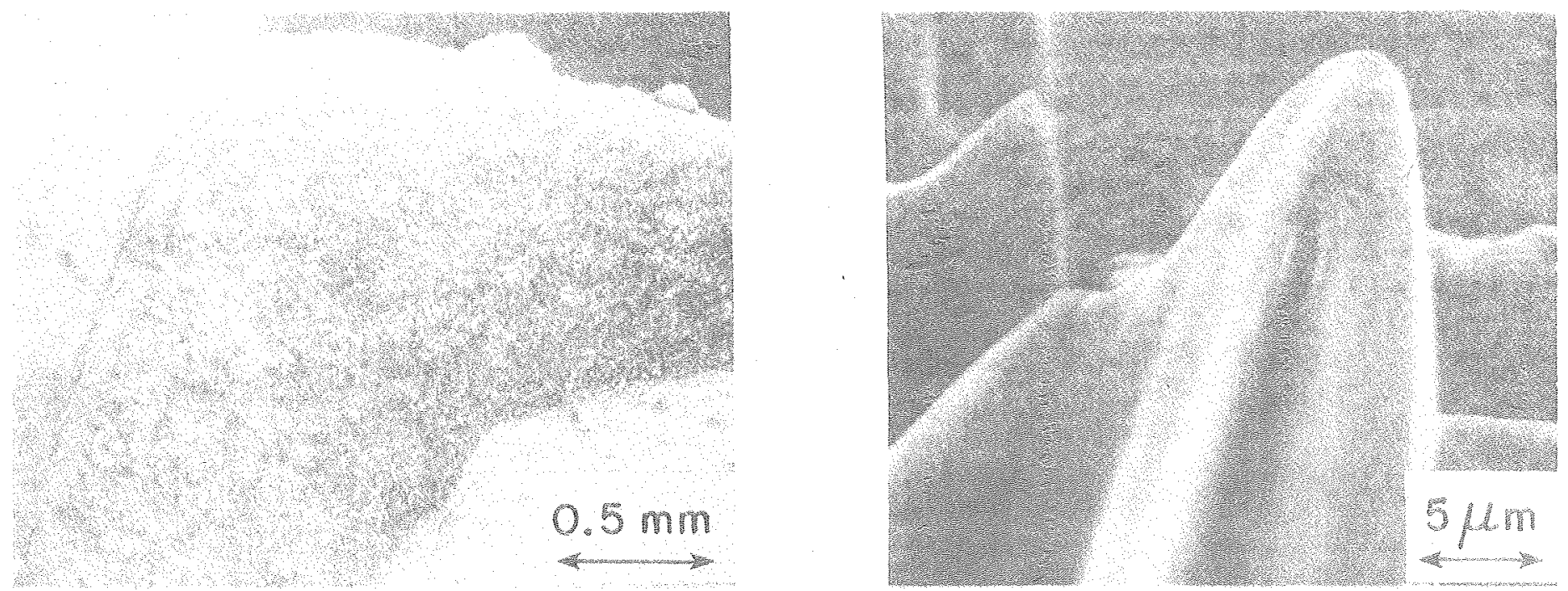

(a)

(b)

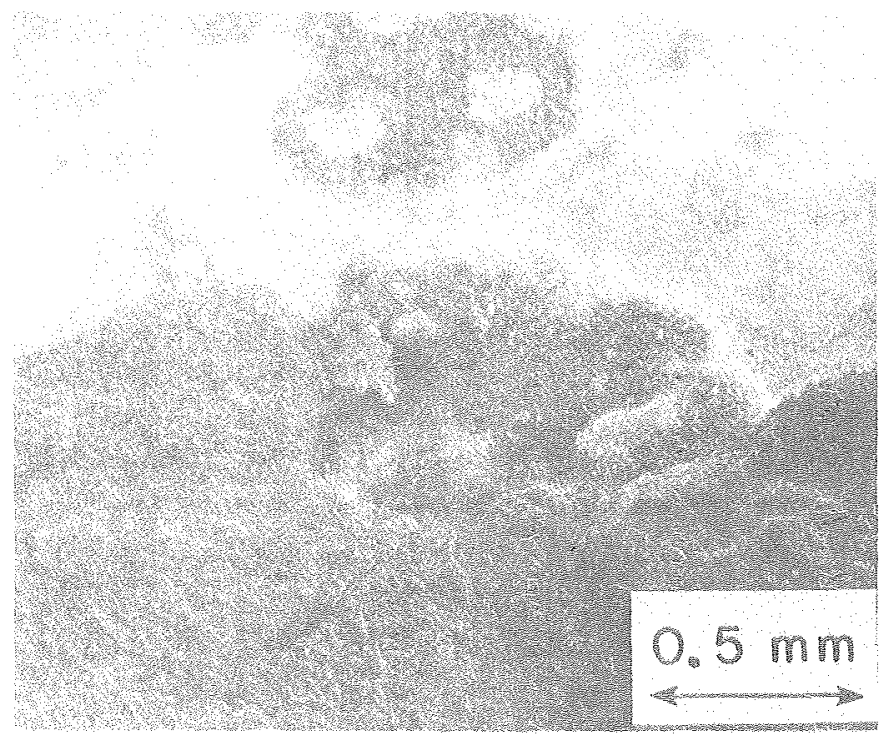

(c)

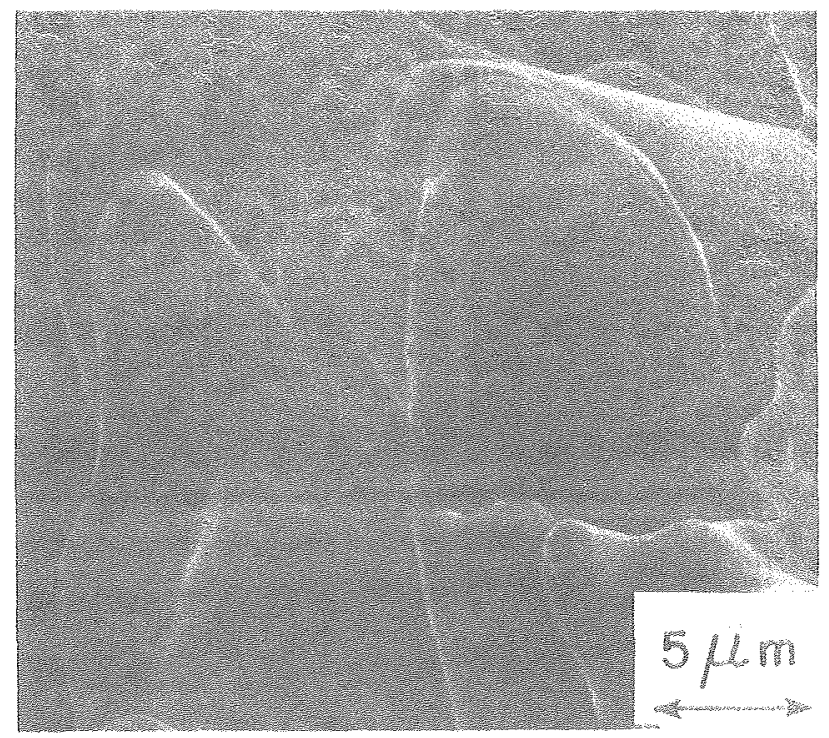

(d)

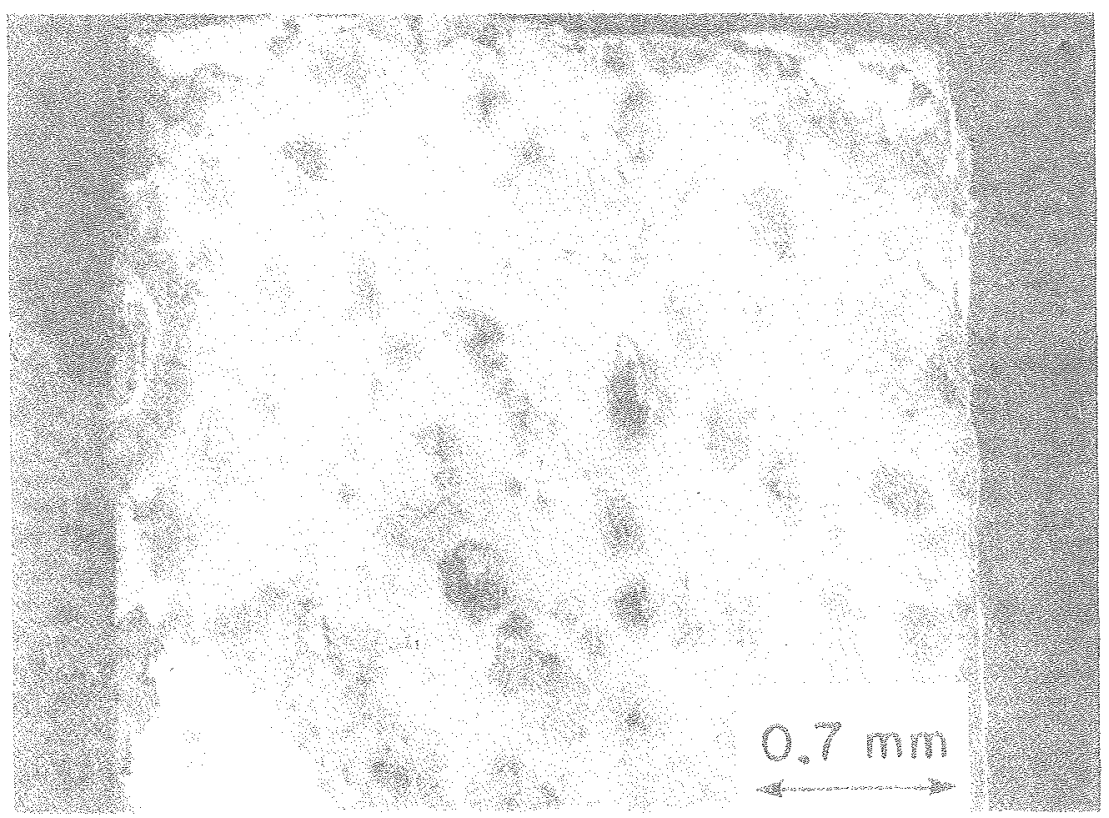

(e) 
Figure 3. Optical micrographs of cross-sections of alloys after 100 hours exyosure. (a) Fe-10AI. (b) Fe-10A $-5 \mathrm{Cr}$. In both, the dark needles represent internal formation of aluminum-rich sulfides within the alloy itself. This region is covered by a scale which is predominantly iron oxide. 


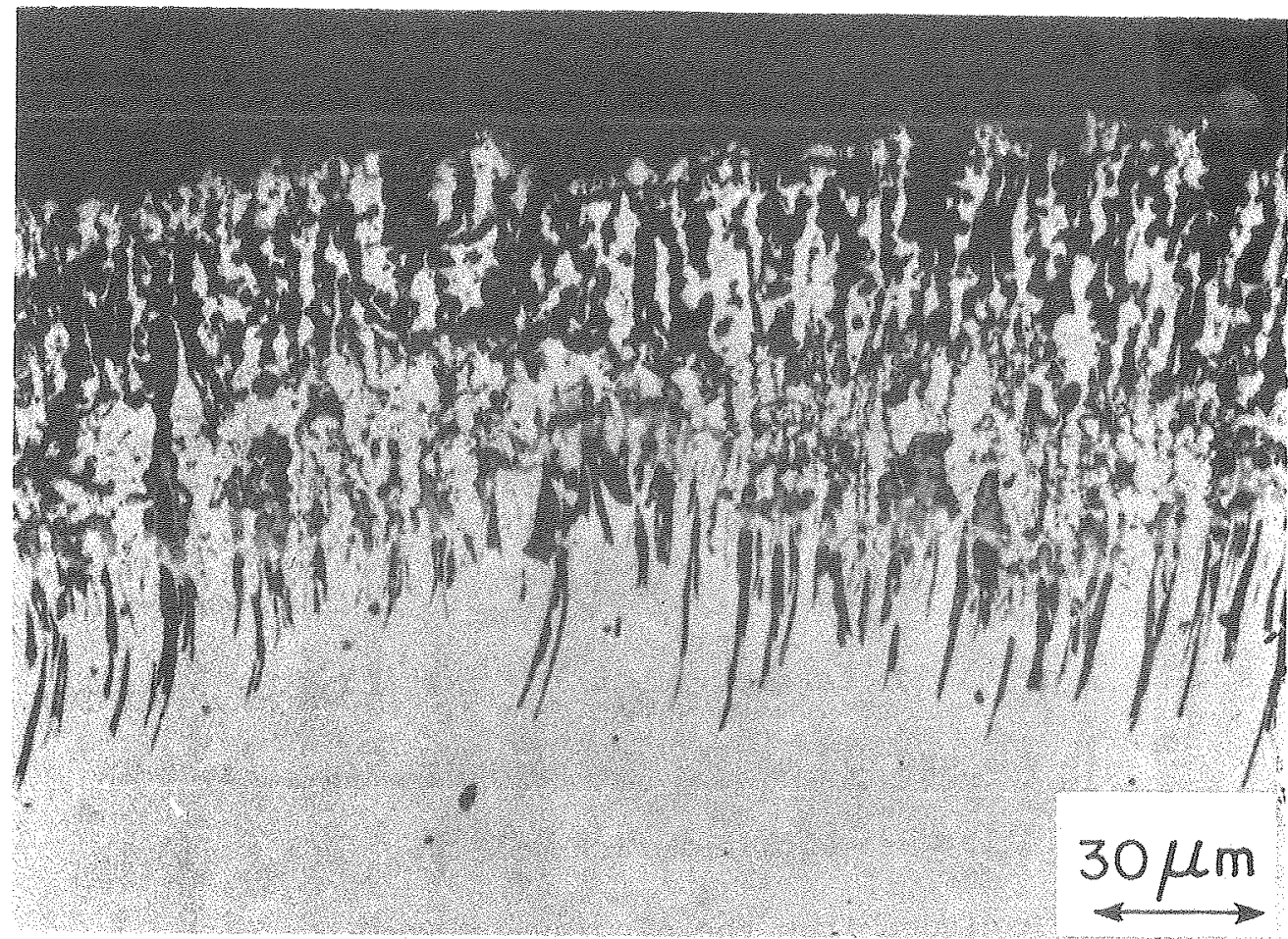

(a)

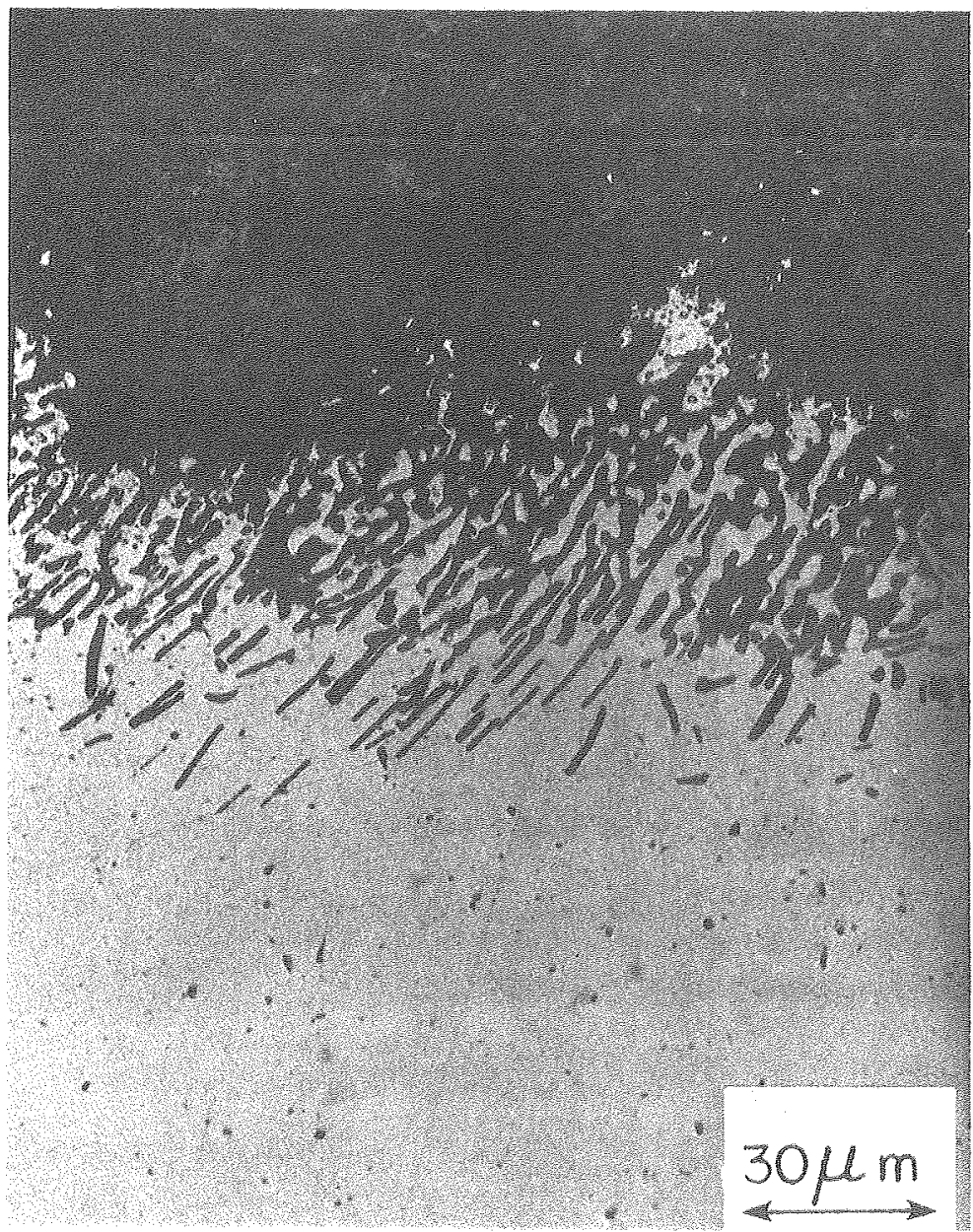

(b) 
Figure 4. Cross section and z-xay mappings of Fe-10A1-5Cr alloy after 100 hours exposure. (a) Electron image. (b-e) elemental maps as indicated. Note the four distinct regions in the cross section: 1) lightest gray region is alloy itself, 2) medium gray at top of (a) is a chromium oxide (see e), 3) darker gray below that is aluminum oxide (see $c$ and $d$ ), and 4 ) the dark gray inclusions in bulk of alloy are aluminum-rich sulfides (see $c$ and d). Iron is excluded from the aluminum-containing regions (see b). 

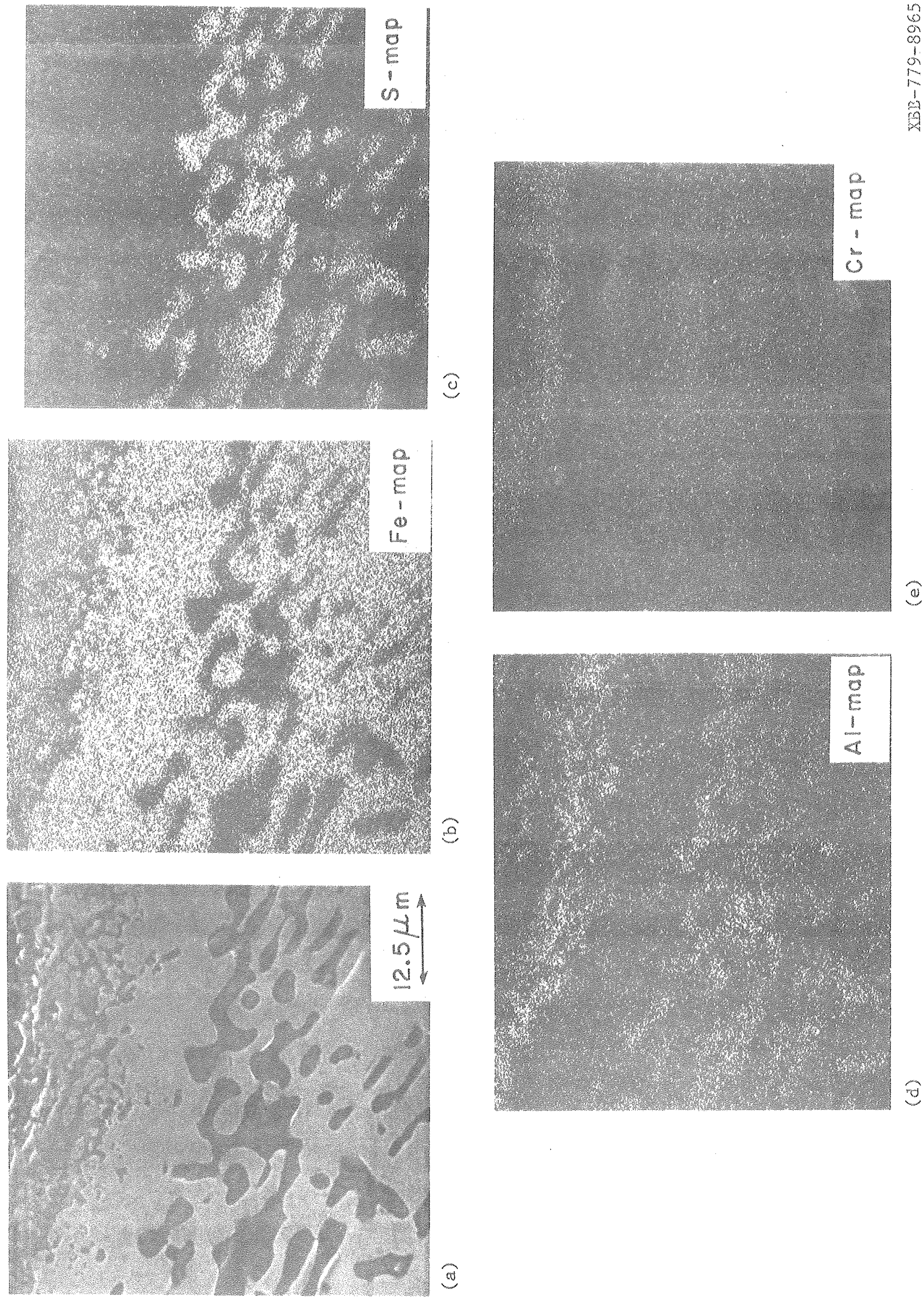
This report was done with support from the United States Energy Research and Development Administration. Any conclusions or opinions expressed in this report represent solely those of the author(s) and not necessarily those of The Regents of the University of California, the Lawrence Berkeley Laboratory or the United States Energy Research and Development Administration. 